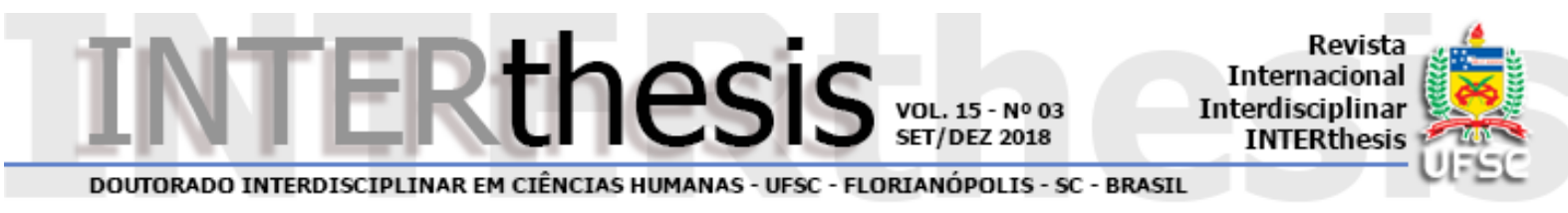

\title{
"OS SENTIMENTOS ELES NUNCA VÃO INDENIZAR": TECENDO MEMÓRIAS DE MULHERES RIBEIRINHAS ATINGIDAS POR BARRAGENS
}

Ana Daisy Araújo Zagallo ${ }^{1}$

Marina Hainzenreder Ertzogue ${ }^{2}$

\section{Resumo:}

O presente artigo tem por objetivo abordar a vulnerabilidade emocional das mulheres ribeirinhas atingidas pela Usina Hidrelétrica de Estreito (MA/TO), com ênfase no registro da história de vida de mulheres idosas, remanescentes da llha de São José, em Babaçulândia (TO). A desestruturação do modo de vida das comunidades rurais tornou as mulheres desterritorializadas vulneráveis não apenas em relação aos aspectos econômicos, mas, sobretudo, os aspectos emocionais e simbólicos causados por perda do modo de vida tradicional. Analisamos a relação afetiva com o rio, o lugar de vivência e a memória. Diagnosticamos que a vulnerabilidade afetiva decorrente do deslocamento trouxe para elas, além do sentimento de incertezas quanto ao futuro, tristeza e depressão. Tais impactos não são relevantes em estudos ambientais apresentados por empreendedores do setor hidrelétrico e tampouco há mitigação prevista, embora, estudos na área do direito ambiental apontem para a necessidade de indenização por danos de valor afetivo.

Palavras-chave: Barragens. Território. Mulheres Ribeirinhas. Vulnerabilidade Afetiva.

\section{INTRODUÇÃO}

Os sentimentos eles nunca vão indenizar. Tomando de empréstimo as palavras de Claides Helga Kowahld ${ }^{3}$ este artigo demonstra como o deslocamento de pessoas de seu habitat, em razão da construção de grandes barragens, causou danos irreparáveis às comunidades rurais tais como o rompimento de laços afetivos de vizinhança e a desestruturação do modo de vida das populações tradicionais que utilizam os recursos naturais para subsistência.

Em 1980, quando a comunidade Água Verde, em Marcelino Ramos (RS), recebeu a notícia da construção de 25 barragens na bacia do rio Uruguai, a

\footnotetext{
1 Doutoranda do Programa de Pós-Graduação em Ciências do Ambiente da Universidade Federal do Tocantins e docente da mesma universidade, Araguaína, TO E-mail: anadaisy@uft.edu.br

2 Doutora em História Social pela Universidade de São Paulo. Professora no curso de História, no Programa de Pós-Graduação em Ciências do Ambiente, em Comunicação e Sociedade da Universidade Federal do Tocantins, Araguaína, TO E-mail: marina@uft.edu.br

${ }^{3}$ Primeira mulher integrante da Comissão Regional dos Atingidos por Barragens (CRAB) no Rio Grande do Sul.
} 
inquietação de Claides Helga, vivendo há 38 anos na mesma comunidade, representava a incerteza dos moradores de Água Verde: - Para onde nós vamos? (WEIMANN, 2013, p. 1). Diante daquele cenário, destacamos a atuação da CRAB em relação à concessionária Eletrosul ${ }^{4}$.

A CRAB buscava questionar o conceito de ambiente utilizado pela Eletrosul que se restringia ao manejo dos meios físico e biótico, como controle da água, para que não comprometesse a vida útil das turbinas, e controle do assoreamento do reservatório, para garantir que fosse acumulada a quantidade de água necessária para a geração de energia. Nesta perspectiva. O ambiente que a Eletrosul destacava era o "ambiente do setor elétrico", no qual a população humana afetada era apenas mais um elemento constituinte desse ambiente (FOSCHIERA, 2010, p. 119).

Segundo o Plano Diretor de Meio Ambiente para o Setor Hidrelétrico, o deslocamento da população afetada e os acréscimos de infraestrutura que nortearam o Plano Global de Remanejamento das Populações Atingidas pela UHE Itá - SC (1987) foi resultante de longo processo de negociação com a Comissão Regional dos Atingidos por Barragens (ELETROBRAS 1990, p. 114). Nesse cenário da região Sul, a CRAB foi um movimento pioneiro que abriu espaços de negociações com a estatal federal Eletrobras. Depois da CRAB, a luta dos atingidos por direitos continuou com a criação do Movimento dos Atingidos por Barragens (MAB), em março de 1991, durante $01^{\circ}$ Congresso Nacional de Atingidos por Barragens.

A abrangência desse movimento tornou-se palpável também na região Norte do país a partir de 2011, início da construção da Usina Hidrelétrica de Estreito (TO/MA). O MAB mobilizou as comunidades rurais e organizou a resistência dos atingidos, mas aproximadamente 42 famílias que não tiveram acesso à terra ou indenizações pagas pelo consórcio da UHE de Estreito permanecem acampadas em uma área verde, próxima do reservatório da usina. Parte dos acampados é remanescente da Ilha de São José, submersa pela barragem ${ }^{5}$.

\section{ITINERÁRIO DA PESQUISA}

Caracterização da área de estudo: o município de Babaçulândia fica na região do Bico do Papagaio (TO). O município teve sua origem no povoado Nova Aurora do

\footnotetext{
${ }^{4}$ Empresa pública controlada pela Eletrobrás e vinculada ao Ministério de Minas e Energia. É uma sociedade de economia mista de capital fechado. Atua nas áreas de geração, transmissão, comercialização de energia.

${ }^{5}$ A UHE de Estreito fez parte do Programa de Aceleração do Crescimento (PAC) do Governo Federal. Em 2002, o grupo Consórcio Energia Estreito (CESTE) venceu o leilão da Agência Nacional de Energia Elétrica para execução do empreendimento.
} 
Coco, em 1926, sob a influência do extrativismo do coco babaçu. Em 1938 passou a chamar-se Babaçulândia, terra do babaçu. Trata-se de um município ribeirinho que fica próximo ao rio Tocantins. Em 2005, quando o IBAMA emitiu a Licença Prévia para autorização da UHE de Estreito, na divisa do Tocantins com Maranhão, a população local ficou apreensiva com os impactos da barragem.

A preocupação presente entre os moradores de Babaçulândia é a construção da Usina Hidroelétrica de Estreito (UHE), cuja barragem deve atingir cerca de 300 casas, ou seja, $90 \%$ da cidade. Os agricultores da região sentem-se prejudicados porque as terras próprias para o cultivo estão próximas ao rio, e afirmam que o restante é infértil. Acabará também a temporada de praia e a Ilha de São José que é muito importante para o turismo e agricultura de Babaçulândia (TOCANTINS, 2005, p. 76).

Depois do enchimento do lago da UHE de Estreito (2011), a llha São José onde segundo o MAB (2010) residiam 142 famílias, ficou completamente submersa. Uma parcela dessa população, composta de pescadores, vazanteiros, extrativistas, entre eles, posseiros e agregados que viveram na ilha há mais 40 anos, sem receber indenização, decidiram ocupar uma faixa de terra, próxima da usina. Valderice Pereira da Silva, 47 anos, liderança do MAB, recordou a formação do acampamento llha Verde.

Quando acabou [a ilha] o que a gente fez? Aí eu reuni umas famílias, nós montamos o acampamento Ilha Verde, já faz quatro anos. Hoje tem lá um grupo de famílias que tão plantando, tão colhendo, tão fazendo feira aqui em Babaçulândia. De lá eles tiram a alimentação, colocam os meninos deles na escola e tem ônibus para ir buscar os alunos, tem o caminhão para ir buscar as coisas da feira. (Entrevistada em 11 nov. 2015).

As entrevistas para realização do presente artigo foram realizadas no acampamento Ilha Verde, entre 2014 e 2016. As entrevistadas eram mulheres idosas, renascentes da llha de São José. Percebeu-se, através de relatos de vida, o inconformismo pelo rompimento dos laços comunitários e a tristeza pela desestruturação do seu modo de vida.

Para essas mulheres o ato de rememorar a llha de São José evocava sofrimento. Por essa razão, "algumas pessoas podem preferir guardar as suas memórias como uma forma de evitar a dor" (ERRANTE, 2000, p. 155). Em Ruídos da memória, Marina Maluf (1995, p. 31) explica que a rememoração é marcada pela reconstrução do presente.

Tal qual o historiador cujo trabalho é o de reconstruir significações pretéritas a partir de seus condicionantes presentes, a relembrança é uma reconstrução orientada pela vida atual, pelo lugar social e pela imaginação daquele que lembra. Nada é esquecido ou lembrado no trabalho de recriação do passado que não diga respeito a uma necessidade presente daquele que registra. 
A fala das mulheres idosas é esclarecedora para entender o processo de ocupação da llha de São José. Antigamente a ilha era uma terra comum, "como diz o povo", era de quem chegasse. Quem tivesse "um gado ou fosse roceiro" entrava. O registro da ocupação é algo significativo para o reconhecimento dos ilhéus como atingidos pela barragem de Estreito.

Maria Isaura de Queiroz (1988) afirma que é preciso observar os avanços e recuos no tempo que marcam as histórias de vida. "O bom pesquisador não interfere para restabelecer cronologias, pois sabe que também estas variações no tempo podem constituir indícios de algo que algo permitirá a formulação de inferências" (QUEIROZ, 1988, p. 20).

Escolhemos o método da história oral de vida na expectativa de compreender "os significados e sentidos das ações e relações entre pessoas ou grupos" (SILVA e BARROS, 2010, p. 69). Quem conta sua história, "faz um apelo à memória para ressignificar o vivido, conferindo-Ihe uma coerência que constrói, organiza e justifica seu ponto de vista". Ainda, de acordo com Silva e Barros (2010, p. 69), ao relatar sua história de vida, o narrador "concatena parte dos fatos e eventos que a constituíram de acordo com a situação e com as relações que ocorrem durante a própria narrativa".

Foram entrevistadas mulheres com idade variável entre 37 a 80 anos, a maioria com pouca escolaridade e baixa renda. Na ilha de São José elas sobreviviam do extrativismo de coco babaçu, pesca e do comércio informal durante a temporada de praia. Todas as lembranças estavam vinculadas ao rio Tocantins, espaço de convivência, lazer e sustento dos ribeirinhos.

Vivendo no acampamento, elas ainda relutavam em aceitar o deslocamento induzido pela barragem e conservam na memória as lembranças da ilha onde havia fartura em alimentos e o bem viver em comunhão com a natureza.

Em Risco ou vulnerabilidade social? Rosane Janczura (2012) discorre amplamente sobre duas concepções que estiveram associadas em diferentes contextos histórico-sociais. A concepção que se aplica neste artigo é a que define vulnerabilidade social como a exposição a riscos e a baixa capacidade material, simbólica e comportamental de famílias e pessoas para enfrentar e superar os desafios com que se defrontam (JANCZURA, 2012; CARNEIRO \& VEIGA 2004).

A partir do conceito de vulnerabilidade social podemos inferir que 0 deslocamento de pessoas idosas, induzido por obras de grandes barragens, expõe 
esta parcela da população a riscos, tais como depressão, tristeza, melancolia e até mesmo incapacidade ao enfrentamento de novos desafios.

\title{
3 "PESCADOR NÃO PESCA NO POÇO, SÓ PESCA NO RIO"
}

Antes da construção da barragem de Estreito, o Estudo de Impacto Ambiental (2002) demonstrou que as comunidades rurais dependiam essencialmente do rio Tocantins para sua subsistência, transporte e lazer.

\begin{abstract}
De maneira geral a população rural apresenta condições de vida mais precárias que à urbana, contribuindo para tal quadro, principalmente, a distância dos equipamentos de saúde e, no caso da educação, a ausência de escolas devidamente equipadas. Residindo, na sua maioria, nas proximidades do rio Tocantins e seus afluentes, esta população possui uma relação bastante estreita com o rio, tanto para sua subsistência, pescando e cultivando nas vazantes, como enquanto meio de transporte e lazer (EIA/RIMA, 2002, p. 60).
\end{abstract}

O território não se define pelo princípio material de apropriação, "mas por um princípio cultural de identificação ou, se preferirmos, de pertencimento. Este princípio explica a intensidade da relação ao território" (HAESBAERT, 2007, p. 50). O rio Tocantins pode ser definido como um território de pertencimento para a população ribeirinha. Maria Barros, uma senhora franzina e de cabelos brancos, sentada na soleira da porta de casa, de onde ainda podia enxergar o Tocantins, fez uma triste profecia:

Convivi demais com o rio. Não tô mais convivendo porque não tenho mais muita coragem de ir lá em baixo, mas daqui tô matando minha saudade de olhar pra ele toda hora, vai acabar tudo né? Vai acabar o nome de rio Tocantins, rio afogado e morto também porque ele não vai significar mais nada (TOCANTINS, Rio Afogado. Documentário, 2005).

Bonnemaison e Cambrezy (1996), citados por Haesbaert (2007), sustentam que o poder do vínculo territorial revela que o espaço é algo investido de valores não apenas materiais, mas também éticos, espirituais, simbólicos e afetivos. Por esse motivo a ligação dos povos tradicionais com o lugar vivido é intensa. Sobre o pertencimento, ouvimos Maria Aparecida, pescadora, 54 anos, acampamento Ilha Verde, entrevistada em 11 set. 2015.

Porque eu não quero ficar longe do rio. Eles (funcionários do Ceste] vieram aqui e eu falei para eles eu não quero. Pescador não pesca no poço, e eu falei isso pra eles. Pescador não pesca no poço, só pesca no rio. E eu tenho meu material de pesca e tenho minha canoa e eu quero pescar no rio. 
As falas de Maria Barros e Maria Aparecida revelam que o território não pode ser percebido apenas como posse ou algo exterior à comunidade que nele habita. "É uma parcela de identidade e fonte de uma relação afetiva ou mesmo amorosa ao espaço" (HAESBAERT, 2007, p. 51).

O território é, na visão de Saquet (2009, p. 81), produto de ações históricas que se concretizam em momentos distintos e sobrepostos, gerando diversas paisagens. Para o autor, o espaço corresponde "ao ambiente natural e ao ambiente organizado socialmente, com destaque para as formas/edificações e para as formas da natureza. Há unidade entre natureza e sociedade".

Retornado a fala de Maria Aparecida, pescadora, remanescente da llha de São José. Antes da usina, o rio era seu lugar de vivência e sustento. "Eu trabalhava na beira do rio, [agricultura] de vazante e pescaria". Antes da barragem chegar, era na vazante e na pescaria que ela tirava o sustento da família. "Quando chegava na piracema eu ficava trabalhando de vazante. Aí veio o pessoal do Ceste..." Percebese pela fala da pescadora que a presença dos funcionários do Consórcio da UHE, antes mesmo da inundação do lago, era o prenúncio da perda de postos de trabalho.

Maria Aparecida demonstrou muita disposição para defender seu modo de vida. "Eu falei para eles que eu não liberava a parte do rio pra eles tudo assim, no momento, eles tinham que me ceder um ponto do rio porque eu tenho mais de dez anos de carteira de pescadora e eu não gosto de ficar longe do rio" (Entrevistada em 11 nov. 2015).

Para Saquet (2009) a territorialidade é um fenômeno social que envolve indivíduos que fazem parte de grupos sociais, onde existem continuidades e descontinuidades no tempo e espaço. "As territorialidades estão intimamente ligadas ao lugar: elas dão the identidade e são influenciadas pelas condições históricas e geográficas de cada lugar" (SAQUET, 2009, p. 88).

Entre as populações atingidas, conforme o relatório da Comissão Especial Atingidos por Barragens do Conselho de Defesa dos Direitos da Pessoa Humana (2010, p. 54) são considerados vulneráveis: mulheres, idosos e crianças que "encontram maiores obstáculos para a recomposição de seus meios e modos de vida".

O Conselho defende o direito de proteção à família e a manutenção de redes de solidariedade. Considerando que o deslocamento, na maioria das vezes, implica na separação de grupos familiares extensos. São redes de solidariedade aquelas que, fundadas no parentesco e nos laços de vizinhança, desempenham papel fundamental 
para a coesão social e, mesmo, para a subsistência do grupo, por ajuda mútua ou mutirões. (CDDPH, 2010).

O Plano Diretor de Meio Ambiente da Eletrobras (1990) responsável pelo setor elétrico brasileiro recomenda que o Plano de Remanejamento da População Atingida, parte integrante do Estudo de Impacto Ambiental EIA, contemple a recomposição do modo de vida da população atingida por barragem.

O remanejamento de grupos populacionais afetados por empreendimentos do setor Elétrico deve visar a recomposição de seus quadros de vida num nível de qualidade pelo menos igual, e preferivelmente superior, ao que era usufruído antes da intervenção do setor. Deve visar, também, a rearticulação do espaço regional, assegurando-se a reorganização da economia, com o desenvolvimento de atividades e serviços de apoio à população (ELETROBRAS, 1990, p. 39).

Da mesma forma, as Diretrizes Ambientais para Projeto e Construção de Barragens, documento do Ministério de Integração Nacional (BRASIL, 2005, p. 28) afirma que ao se retirar uma comunidade de seu habitat físico e social, isso "pode acarretar aspectos negativos que não têm solução ótima. Porém, na medida do possível, deve-se tentar oferecer condições para a reconstrução desse habitat".

O texto reconhece que a remoção involuntária de uma família pode acarretar custos sociais "que vão além dos custos financeiros com o pagamento de transporte, impostos e outros gastos que antes não faziam parte de suas despesas". (BRASIL, 2005, p. 28). São os custos associados à desestruturação de laços de vizinhança e redes de sociabilidade.

Há uma grande distância entre o planejado e o vivido. As diretrizes de órgãos governamentais ligados ao meio ambiente orientam que os empreendedores apresentem um projeto de recomposição das condições de vida dos impactados no Estudo de Impacto Ambiental com a elaboração do Plano de Remanejamento da População Atingida. Todavia, na prática a recomposição das condições do modo de vida dos impactados não são viabilizadas.

De acordo com o documento do $\operatorname{MAB}$ (2010, p. 1), "Brazil: Women affected by dams - changes in their lifestyles" divulgado no WRM ${ }^{6}$ Bulletin 152, as populações ribeirinhas perderam as condições materiais de subsistência e vínculos afetivos com o lugar quando foram deslocadas compulsoriamente.

\footnotetext{
${ }^{6}$ World Rainforest Movement (WRM) é uma rede internacional que visa contribuir para lutas, reflexões e ações políticas de povos dependentes de florestas, indígenas, camponeses e outras comunidades do Sul global sendo formada por ativistas de diferentes partes do mundo.
} 
[...] transplantadas geograficamente e culturalmente, expropriadas de um saber e de uma sintonia com o meio físico, a sua vizinhança, com valores "abstratos", porém de grande importância sentimental e principalmente referencial, os quais jamais serão reconstruídos, nem podem ser medidos pelo dinheiro.

Reis e Bloemer (2001, p. 12) advertem sobre a desocupação de grandes extensões de terras onde vivem diferentes segmentos sociais, "tornando-se indispensável a retirada compulsória de populações que historicamente vinham ocupando esses locais". A realocação significa o banimento do lugar vivido sem opção de recusa.

A distância do rio é fato, considerando-se que os reassentamentos estão longe do reservatório. Segundo Rebouças (2000) a distância se justifica por questões de segurança, probabilidades de alagamento ou alteração do regime de funcionamento da usina. $\mathrm{O}$ autor, entretanto, reforça que o afastamento do contato com a água resulta na ruptura do modo de vida de comunidades caracterizadas pela proximidade com o rio. Isso significa que a mudança para reassentamentos planejados, com outra forma de ordenação social, implica estabelecer condições distintas do modo de vida que levavam.

\section{DESLOCAMENTOS, PERDAS E DANOS}

Sobre o dano moral decorrente da expropriação do lugar, Rezende (2002) ressalta que o valor de afeição pode ocorrer em qualquer relação de propriedade ou posse, "desde que seja gerada uma ligação sentimental da pessoa com o bem" (REZENDE, 2002, p. 84). O autor classifica as perdas imateriais ou danos em: a) Valor de afeição é o que está associado ao proprietário e sua ligação com a terra, a história de vida, família e comunidade; b). Dano à vida de relação que é a pela perda de laços culturais e do modo de vida; c) Dano ao direito de viver bem que está relacionado à saúde mental e física das populações impactadas.

O valor afetivo mencionado por Rezende está intimamente ligado ao local de vivência e com a experiência de uma pessoa ou grupo. No caso das populações ribeirinhas, essa ligação com a natureza se manifesta nas práticas culturais, lazer e fonte de sobrevivência. Para Yi-Fu Tuan, os laços afetivos com o meio ambiente têm diferentes intensidades e modos de expressão: o convívio com a natureza, o prazer de sentir o ar, a água, a terra. "Difíceis de expressar são sentimentos de lugar, por ser o lar, o locus das reminiscências e o meio de se ganhar a vida" (2012, p. 136). 
O sentimento de afeição e pertencimento ao lugar denomina-se topofilia, isto é, o elo afetivo entre a pessoa e o ambiente físico. "Difuso como conceito, vivido e concreto como experiência pessoal" (TUAN, 2012, p. 5). A experiência descrita por Tuan (2012, p. 19) pode ser reconhecida na fala Dona Raimunda, 52 anos, ribeirinha impactada pela barragem do rio Tocantins, entrevistada em maio de 2014.

Oh, meus Deus! Eu vou trabalhar agora, mas quando eu tiver 60 anos, só na rede e os pés balançando. Aquela árvore de copa na beira do rio, um pé de sapucaia carregado. Vou atar minha rede de baixo do pé de sapucaia e só balançar. Foi tudo contrário meus sonhos. Foi tudo para o fundo do poço.

A perda de determinado modo de vida remete ao impacto social relacionado com as perdas imateriais: a perda da vida de relação. Remoção não é simplesmente a transferência de um espaço para outro com compensações por danos materiais.

\footnotetext{
Todo espaço físico humanamente ocupado é um espaço socialmente construído, é um espaço que se transforma pelo vivido, pelo cotidiano, pelo conjunto das relações sociais que o constituem. Portanto, espaço social com todas as suas dimensões: mítica, sagrada, de representação [...]. No caso de relocações compulsórias de populações esta dimensão tem sido afetada, criando situações denominadas de stress psicológico e social (SCHERER-WARREN, 2011, p. 86).
}

O sofrimento ambiental decorrente do deslocamento é perceptível entre pessoas de idade avançada que viveram sempre no mesmo lugar. Observamos no olhar das mulheres muita tristeza e melancolia. Para elas, os reassentamentos não oferecem condições para recomposição do modo de vida.

No âmbito jurídico, Leandro Rezende (2002) defende que o valor de afeição por perda de um lugar seja mitigado pelo empreendedor. Portanto, quando se fala em impactos ambientais, não pode ser considerado apenas os danos materiais da população expropriada, de acordo com Rezende (2002, p. 79), "todo o dano imaterial sofrido por essas populações deve ser devidamente compensado, dando-se ao conceito de dano moral o mais amplo sentido".

Sobre os efeitos da desterritorialização: as mulheres idosas têm mais dificuldade na recomposição do seu modo de vida, além disso, elas lamentam a perda de atividades informais que gerava uma fonte de renda familiar.

Dona Dalva, 63 anos. "Eu vendia, na temporada da praia. Eu vendia comida e fazia tudo na minha casa. Então eu tinha minha rendinha, meus perfumes". (Entrevistada em 26 mar. 2015). Além disso, a perda dos vínculos comunitários trouxe consequências severas para mulheres que dependiam de ações colaborativas, segundo WRM Bulletin (152, 2010, p. 1). 
O empobrecimento gerado pelo deslocamento compulsório das pessoas e a chegada truculenta dessas grandes obras, aumentam os desentendimentos, a desestruturação familiar, o abandono das famílias e a migração masculina para as áreas urbanas, elevando o número de casas chefiadas por mulheres, que passam a arcar sozinhas com toda a responsabilidade da criação dos filhos.

Com deslocamento compulsório podemos inferir que a população idosa perdeu as condições de recompor seu modo de vida e que entre as causas destaca-se a quebra de redes de solidariedade e perda de renda gerada pelo comércio informal e o turismo no rio Tocantins.

\section{HISTÓRIAS DE VIDAS SUBMERSAS}

Em 2010, quando o Ceste finalizou a desapropriação das áreas impactadas e iniciou o enchimento do lago, uma parte da comunidade rural de Babaçulândia não foi reconhecida para efeitos de indenização pelo Consórcio da UHE Estreito. Segundo o coordenador do $\mathrm{MAB}$, trata-se de posseiros e trabalhadores que tinham atividades ligadas ao com o rio.

Cerca de 1150 famílias de pescadores, extrativistas, filhos de proprietários e posseiros não foram indenizados. Esta é uma região com temporadas bem definidas de seca e de chuvas. Na época de seca, o rio baixa e as pessoas usufruem dele como praia e, com isso, há barqueiros que levam as pessoas até à praia e barraqueiros que vivem da venda de cerveja, peixe e outras coisas durante os meses de junho, julho e agosto. A empresa também não reconheceu essas categorias. (Cirineu Rocha, entrevistado em 01 de set. 2010).

Com a barragem, ambulantes, pescadores e barqueiros que desciam pelo rio até a Praia do Coco transportando passageiros e mercadorias perderam postos de trabalho. A llha São José com $12 \mathrm{Km}$ de extensão, coberta por babaçuais, as casas feitas com palha de palmeira e uma natureza exuberante era uma atração turística da região.

Segundo o EIA da UHE de Estreito, a população rural impactada se caracterizava pelas relações de parentescos e vínculos comunitários, além da condição de vulnerabilidade justificada "por causa do baixo grau de escolaridade e de capacitação profissional e particularidades no seu modo de vida" (CNEC, 2005, p. 10). Apesar do reconhecimento da vulnerabilidade, não houve mitigação para os danos sociais ou recomposição do seu modo de vida.

Também entre as famílias reassentadas em Babaçulândia pelo Consórcio Estreito Energia percebeu-se a insatisfação das mulheres idosas por causa da 
ausência do rio e da falta da roça na vazante. Dona Magnólia, 80 anos de idade, antiga moradora da llha de São José, não se adaptou na cidade.

"Minha vida aqui é só capinar o cercado e plantar uma coisinha para comer. Crio um franguinho e o povo rouba, já roubaram três vezes galinha minha. Lá [na ilha] podia criar galinhas solta dentro das quintas mesmo". (Entrevistada em 26 mar. 2016). Dona Magnólia nasceu no Cercado, lugar que ficava perto do rio.

A barragem para ela foi uma fatalidade.

Pois é eu sou de [19] 35, um bocado de janeiro (risos). Foi no Cercado lá, o nome é cercado onde nasci, na beira do rio. Lá era bom tinha muitas coisas e tinha um sítio que valia a pena, tudo de cerca, tudo plantadinho... animal. Vivia tranquila. Aí chegou a barragem e acabou com tudo.

As idosas tinham saudades da ilha e dos laços afetivos de vizinhança. Dona Capucho, 79 anos, quebradeira de coco. Ela espera que a barragem seque algum dia para voltar a viver em São José.

Meu nome é Capucho (risos), é apelido, desde molinha, eu gosto de capucho. Na ilha, gostava, gostava mesmo, você podia deixar o arroz enxugando e podia ir no rio, quando vinha era com a mistura, aqui só não compra Deus, mas o resto... A minha lida era de quebrar coco, fazer carvão, plantava tudo na vazante que eu tinha. Aqui vivo nessa situação... (Entrevistada em 31 mar. 2015).

Dona Maria do Carmo, maranhense, 73 anos, viveu na llha de São José por mais de meio século. Descreve o ressentimento de ter sido despojada de suas memórias.

Só lá foi 68 anos que eu morei. Desde que meus pais vieram de Grajaú, no Maranhão, que eu nem conheço lá, eu vim nos panos. Pois é... 68 anos. Meus pais morreram, enterrados aqui [...] desde que meus pais vieram do Maranhão, desde molinha que eu vim, cheguei com 4 meses de idade. Toda vida morando aqui na beira do rio. Meus irmãos mudaram... moravam em Miracema ... Da minha geração tem eu só (Entrevistada em 31 mar.2015).

Somando-se os impactos emocionais pela perda do lugar de vivência ao rompimento dos laços comunitários, observa-se algo ainda mais tangível na vida destas mulheres: a desestruturação de pequenas unidades produtivas familiares.

\section{DESESTRUTURAÇÃO DE UNIDADE PRODUTIVA DA FAMÍLIA RURAL}

Com a construção da UHE de Estreito, na divisa do Tocantins e Maranhão, o Estudo de Impacto Ambiental (2002) advertiu sobre o comprometimento do modo de vida típico das populações ribeirinhas. O rio estaria comprometido pelo empreendimento, "face à sucessão de represas que poderá transformar o Tocantins 
em imenso lago." Vinculado ao modo de vida das comunidades rurais, o EIA também advertiu que a perda das praias fluviais afetará a economia de subsistência, "pois é na temporada de praia - entre junho e agosto, que mais se mobiliza essa economia, com a presença de grande número de turistas" (CNEC, 2002, p. 260).

As entrevistadas confirmaram os impactos negativos previstos no EIA. Dona Dalva, 64 anos, vendedora de "geladinho" na Praia do Coco. "Só de geladinho que eu vendia 100, 150 reais. Eu fazia 250, 300 geladinhos na sexta-feira, quando era segunda-feira não tinha mais. No reassentamento ela diz: "Aqui acabou tudo. Eu não vendo nada". (Dalva, entrevistada em 27 mar. 2015).

A importância do rio Tocantins para a economia dos municípios ribeirinhos em épocas de alta temporada foi identificada no Estudo dos Impactos Ambientais da UHE de Estreito.

Outras atividades associadas ao rio Tocantins são o turismo e o lazer da população, envolvendo barqueiros, barraqueiros e ambulantes $e$ as conhecidas praias do Tocantins. A economia de diversos municípios ribeirinhos se movimenta entre os meses de junho a agosto e setembro, em torno das praias. Neste período, o cotidiano dessas comunidades se modifica tanto em função da chegada de visitantes, como devido à movimentação típica das épocas de férias (EIA, 2000, p. 55);

Dona Maria da Graça, 63 anos, vendedora de gelo na Praia do Coco, confirmou o relato do EIA. "Lá, eu pegava uma barcada com 130 barra e no outro dia eu tinha vendido tudo. Aqui [em Babaçulândia] eu pego 120 barras e tem vezes que eu passo 22 dias pra vender elas". (Entrevistada em 22 mar. 2015).

Maria da Graça também revendia leite. Na ilha ela vendia 50 litros por dia. Quando se mudou para Babaçulândia, o entregador deixava diariamente 5 litros. "Então eu falei pra ele: Não traga mais porque eu só tô perdendo meu tempo" (Entrevistada em 25 mar. 2015).

Insatisfeita com a moradia na cidade, Dona Capucho, 79 anos, queria continuar na Ilha de São José, onde havia fartura na época da colheita.

Lá [na ilha] era um rio e isso aí é um lago. Lá era arroz, milho, feijão, fava, abóbora, melancia e batata, tudo eu plantava dentro de minha vazante. Deixava o arroz enxugando e descia pro rio, chegava com o peixinho, era só nós... Na beira do lago ali eu já fui né, não gosto não. Pois é, vivo desse jeito, sofrendo aqui. (Entrevistada em 31 mar. 2015).

Além da desestruturação da unidade produtiva familiar, as entrevistadas relataram a perda dos laços de vizinhança. "Sinto falta dos vizinhos, das pessoas 
amigas. O que eu sinto mais falta [na beira rio] é do setor e dos meus vizinhos". (Dona Maria do Carmo, 75 anos, entrevistada em 22 abr. 2016).

Uma comparação entre os ribeirinhos que foram reassentados pelo Consórcio Estreito Energia e os acampados na Ilha Verde permite inferir que há mais disposição destes em recompor seu modo de vida pelo fato do acampamento ficar próximo do lago, em área verde, no entorno da usina.

No tempo que saímos da llha de São José não tinha onde a gente ficar, nem trabalhar na cidade. Viver de que? Aí viemos para cá pra ver se conseguia plantar alguma coisa. No começo foi construído um único barracão para abrigar as famílias. Depois resolvemos se espalhar para que cada um pudesse ter um pedacinho de terra pra trabalhar perto da água. (Pedrina, 38 anos, entrevistada em 25 set. 2016).

No acampamento Ilha Verde, Aparecida, 46 anos, mãe de 8 filhos, afirmou que próximo da água, os ribeirinhos poderão de algum modo recompor seu modo de vida.

Aqui [no acampamento] eu tô me sentindo muito feliz. Aqui na beira do lago. Não quero ficar na cidade, quero ficar aqui na beira do lago, no sertão, trabalhando como eu venho trabalhando e sustentando meus filhos. Aqui eu pesco, lavo minha roupa, aqui eu durmo bem, aqui eu trabalho na minha horta, tenho honra. Tenho tudo (Entrevistada em 31 mar. 2015).

Grandes empreendimentos hidrelétricos são obras que transformam o trecho de um rio em área de segurança, como enfatizam Valencio e Gonçalves (2006, p. 211), afirmando que a ocupação do território onde o lago está é seletiva.

Assim selecionando os grupos que são autorizados ou impedidos de circular à sua volta. Desta seleção, os grupos locais são afastados, mantidos à distância, mas precisam continuar a ter a obra como referência para ajustamento de suas práticas. Barragens devem, preferencialmente, ser cultuadas de longe. Todavia, algumas representações e práticas sociais locais não se apropriam dos benefícios induzidos pelo empreendimento e sequer das noções de perigo veiculadas.

A fala da jovem Sirlene, entrevistada no acampamento Ilha Verde, ilustra perfeitamente a seletividade descrita por Valencio e Gonçalves. "Tem mansão mais perto do rio que a gente." Enquanto isso, na outra margem do lago, desabafou Sirlene: "Fizeram praia e tudo... E nós? Nós não podemos... Lá, no outro lado não se plantou nada, só tem grama" (Entrevistada em 25 set. 2016).

\section{CONCLUSÃO}

Ao final das entrevistas, o que ficou evidenciado na fala das mulheres atingidas? Enquanto viveram na beira do rio, muitas delas foram economicamente ativas, incluindo as mulheres idosas que geravam renda através do comércio informal 
na temporada de praias. A remoção para os reassentamentos do Ceste liquidou com a fonte de renda originada pelo turismo na Praia do Coco.

Com a desterritorialização ocorreu o empobrecimento e a vulnerabilidade, tanto emocional quanto econômica, das comunidades rurais da Ilha São José. A mudança para o reassentamento do Ceste ou em casa própria na cidade implicou gastos que antes não faziam parte de suas despesas. O deslocamento compulsório da comunidade para lugares distantes do rio impossibilitou a recomposição do modo de vida. Embora, o Estudo de Impacto Ambientai da UHE de Estreito recomendasse a recomposição, isso não foi viabilizado.

O valor de afeição é um tipo de dano moral, conforme defendeu Rezende. Danos são causados pela construção de barragens e apesar de estar ligado a um dano material, não se confunde com este, pois se trata de um dano imaterial, já que atinge o psíquico do indivíduo. Incluindo-se a dissolução de laços de vizinhanças e até familiares. Exemplos de valores de afeição que foram perdidos com o deslocamento foram registrados em entrevistas com mulheres idosas: A saudade do quintal, da sombra do pé de manga e da roupa lavada na beira do rio.

A entrevista com mulheres atingidas pela UHE de Estreito demonstrrou que para os ribeirinhos a qualidade de vida está associada à proximidade com a água e a natureza. Há, por isso, uma convicção entre as mulheres mais jovens que se resume na crença de que para os acampados da Ilha Verde, aquele pedaço de terra perto do lago, se torne um lugar capaz de ressignificar a ilha São José.

“A gente já construiu uma história aqui” (Sirlene, entrevistada em 25 set. 2016). 


\title{
"THEY WILL NEVER COMPENSATE THE FEELINGS": MEMORY WEAVING OF RIVERSIDE WOMEN AFFECTED BY DAMS
}

\begin{abstract}
:
This article aims to address the emotional vulnerability of riverside women affected by the hydroelectric power plant of Estreito (Matogrosso and Tocantins State, Brazil) with emphasis on the recording of the elderly women's life history, remnants in the island of São José in Babaçulândia (Tocantins). The disruption of rural communities' lifestyle made the deterritorialized women vulnerable not only regarding economic aspects, but, above all, in the emotional and symbolic aspects caused by loss of their traditional way of life. We examined the affective relationship with the river, the place of experience and the memory. We diagnosed that the affective vulnerability resulting from the displacement brought sadness and depression, besides the feeling of uncertainty about the future. Such impacts are not relevant in environmental impact studies presented by entrepreneurs from the hydroelectric sector, nor there is a mitigation procedure foreseen, although studies in the area of environmental law state the need to compensate for damages of affective value.
\end{abstract}

Keywords: Dams. Territory. Riverside Women. Emotional Vulnerability.

\section{"LOS SENTIMIENTOS QUE NUNCA COMPENSARÁ": TEJER RECUERDOS DE MUJERES RIBEREÑAS AFECTADAS POR REPRESAS}

\section{Resumen:}

Este artículo pretende abordar la vulnerabilidad emocional de mujeres ribereñas afectadas por la usina hidroeléctrica del Estrecho (estados de Matogrosso y Tocantins, Brasil) con énfasis en el registro de la historia de vida de las mujeres ancianas, población remanente de la isla de São José en Babaçulândia (Tocantins). La alteración de las condiciones de vida de las comunidades rurales las tornó mujeres desterritorializadas vulnerables no sólo en lo referente a los aspectos económicos, sino, sobre todo, en los aspectos simbólicos y emocionales causados por pérdida de la forma tradicional de vida. Examinamos la relación afectiva con el río, el lugar de la experiencia y la memoria. Diagnosticamos que la vulnerabilidad emocional resultante del desplazamiento trajo a ellas, más allá de la sensación de incertidumbre sobre el futuro, la tristeza y la depresión. Estos impactos no son relevantes en los estudios ambientales presentados por empresarios del sector hidroeléctrico y tampoco hay mitigación prevista, aunque, en el área de derecho ambiental estudios señalan la necesidad de compensación por daños de valor afectivo.

Palabras clave: Represas. Territorio. Mujeres Ribereñas. Vulnerabilidad Emocional. 


\section{REFERÊNCIAS}

BRASIL. Ministério da Integração Nacional. Secretaria de Infraestrutura Hídrica. Diretrizes Ambientais para Projeto e Construção de Barragens e Operação de Reservatórios. Brasília: Bárbara Bela Editora Gráfica e Papelaria Ltda, 2005.

CARNEIRO, C. B. L.; VEIGA, L. O conceito de inclusão, dimensões e indicadores. Belo Horizonte: Secretaria Municipal de Coordenação da Política Social, jun. 2004. (Pensar BH - Política Social, 2.

CDDPH - Conselho de Defesa dos Direitos da Pessoa Humana. Relatório da Comissão Especial de Atingidos por Barragens. Resoluções n. 26/06, n. 31/06, n. 01/07, n. 02/07, n. 31/07, Brasília, DF, 2010. Disponível em: < http://www.sdh.gov.br/sobre/participacao-social/cndh/relatorios/relatorio-c.eatingidos-por-barragens >.Acesso em: 22 abr. 2015.

CNEC ENGENHARIA S. A. Estudo de Impacto Ambiental e Relatório de Impacto Ambiental - EIA/RIMA da Usina Hidrelétrica de Estreito. São Paulo, 2002.

. Programa de Ações para Reposição de Perdas e Relocalização da População Rural e Urbana da UHE Estreito. São Paulo, 2005. In: Licenciamento IBAMA (2005). Disponível em:

<http://licenciamento.ibama.gov.br/PBAs\%20Hidrel\%C3\%A9tricas/UHE\%20Estreito/ SOCIOECONOMIA\%20JUL\%2010/3.30.\%20Programa\%20de\%20reloca\%C3\%A7\% C3\%A3o.pdf >. Acesso em: 12 jun. 2016.

ELETROBRÁS - Centrais Elétricas do Brasil S.A. Plano Diretor do Meio Ambiente. (1991-1993). Volumes 1 e 2. Rio de Janeiro: Eletrobrás, 1990. Disponível em: $<$ http://eletrobras.com/pt/EstudantesePesquisadores/acervo documentos tecnicos/P lanoDiretordeMeioAmbiente/pdma volume1.pdf >. Acesso em: 01 set. 2016.

ERRANTE, Antoinette. Mas afinal, a memória é de quem? História oral e modos de lembrar e contar. História da Educação. Pelotas: ASPHE/UFPel, v. 8, 141-74, set. 2000.

FOSCHIERA, Atamis Antonio. Conhecendo a trajetória de organização dos atingidos por barragens. Caminhos de Geografia. Uberlândia v. 11, n. 36, p. 113 - 128, dez. 2010.

JANCZURA, R. Risco ou Vulnerabilidade Social? Textos \& Contextos, Porto Alegre, v. 11, n. 2, p. 301-308, ago./dez. 2012. 
HAESBAERT, Rogério. Concepções de território para entender a desterritorialização. In: SANTOS, Milton. et al. (Org.). Território Territórios. $3^{a}$ ed. Niterói: Lamparina, 2007, p. 43-71.

IBGE. Instituto Brasileiro de Geografia e Estatística. O Brasil em síntese: mapas e pesquisas do IBGE sobre os municípios e estados do Brasil. Disponível em: <https://cidades.ibge.gov.br > Acesso em 10 jun. 2017.

MAB - Movimento dos Atingidos por Barragens. Carta Final do $1^{\circ}$ Encontro Nacional das Mulheres do MAB. $1^{\circ}$ Encontro das Mulheres Atingidas dor Barragens. Brasília, 07 de abril de 2011. Disponível em: $<$ http://www.mabnacional.org.br/noticia/carta-final-do-encontro-nacional-dasmulheres-do-mab >. Acesso em: 20 fev. 2015.

. Brazil: Women affected by dams - changes in their lifestyles. In: WRM Bulletin, $\mathrm{n}^{\circ}$ 152, March, (2010). Disponível em: $<$ https://womenonthemarch.wordpress.com/2010/03/22/brazil-women-affected-bydams-\%E2\%80\%93-changes-in-their-lifestyles/ >. Acesso em: 15 mar. 2016.

MALUF, Marina. Ruídos da memória. São Paulo: Siciliano, 1995.

REIS, Maria José; BLOEMER, Neusa M. Reis. Hidrelétricas e populações locais. Florianópolis: Cidade Futura/Ed. da UFSc, 2001.

IHU- Instituto Humanitas Unisinos. (Entrevista). ROCHA, Cirineu. Usina de Estreito e seus impactos socioambientais. 01 set. 2010. Disponível em:

$<$ http://www.ihu.unisinos.br/entrevistas/35537-usina-de-estreito-e-seus-impactossocio-ambientais-entrevista-especial-com-cirineu-da-rocha >. Acesso em: 22 out. 2015.

QUEIROZ, Maria Isaura Pereira de. Relatos Orais: do "indizível" ao "dizível". in: SIMSON, Olga Moraes Von. Experimentos com Histórias de Vida (Itália-Brasil). São Paulo: vértice, 1988. p. 14-43.

REBOUÇAS, Lídia Marcelino. O planejado e o vivido: o reassentamento de famílias ribeirinhas no Pontal do Paranapanema. São Paulo: Annablume/Fapesp, 2000.

REZENDE, Leonardo Pereira. Dano moral e licenciamento ambiental de barragens hidrelétricas. Curitiba: Juruá, 2002. 
SAQUET, Marco Aurélio. Por uma abordagem territorial. SAQUET, Marco Aurélio e SPOSITO, Elizeu Savério. (Org). Territórios e territorialidades: teorias, processos e conflitos. São Paulo: Expressão Popular/UNESP, 2009.

SCHERER-WARREN, Ilse. Redes de movimentos sociais. $5^{\circ}$ Edição. São Paulo: Loyola, 2011.

SILVA, V. P.; BARROS, D. D. Método história oral de vida. Rev. Ter. Ocup. Univ. São Paulo, v. 21, n. 1, p. 68-73, jan./abr. 2010.

TOCANTINS, Rio Afogado (Documentário). (41:44-42:14). Direção de João Luiz Neiva. Roteiro: Hélio Brito. MINC/ DOCTV 2, Brasil, 2005, DVD.

TOCANTINS. Secretaria do Planejamento e Meio Ambiente - Seplan/ Instituto Natureza do Tocantins - Naturatins. Plano de Manejo do MNAFTO. Dez 2005. Disponível em $<$ https://documentacao.socioambiental.org/ato normativo/UC/2100 201603111657 14.pdf >. Acesso em: 10 mar. 2017.

TUAN, Yi-Fu. Topofilia: um estudo da percepção, atitudes e valores do meio ambiente. São Paulo: Difel, 2012.

VALENCIO, Norma Felicidade Lopes; GONÇALVES, Juliano Costa. Da confiança à fatalidade: colapso de barragens como limite ao paradigma da modernização? Política \& Trabalho: Revista de Ciências Sociais, v. 25, outubro de 2006.

WEIMANN, Guilherme. Os sentimentos eles nunca vão indenizar. (Entrevista com Claides Helga); Movimento dos Atingidos por Barragem. 11 de nov. 2013. Disponível em: < http://www.mabnacional.org.br/noticia/os-sentimentos-eles-nuncav-indenizar >. Acesso em: 15 de nov. 2015. 